\title{
ANTECEDENTES DOCTRINALES DEL REGALISMO BORBONICO. \\ Juristas españoles en las lecturas de los regalistas europeos modernos
}

\section{Antonio BENLLOHC POVEDA}

Doctor en "Utroque iure"

Facultad Teología de Valencia. 

A la hora de tratar el regalismo del XVIII, nuestros historiadores han querido ver un "cambio de sentido del regalismo español bajo los Borbonesw(1). Insisten, por otra parte, en la escasa originalidad del pensamiento español, claramente influenciado por autores extranjeros: Pedro de Marca, Van Espen, Fleury, Febronio. Con ello afirman que es un regalismo (intervención del rey en asuntos eclesiásticos) extraño a nuestra tradición jurídica, y a la vez extranjerizante. También se ha querido ver que esta actitud de nuestros reyes borbones es diferente a la de los Habsburgo. Se ha defendido "ortodoxa a la casa de Austria" y "heterodoxa a la casa de borbón" siguiendo la línea trazada por Menéndez Pelayo(2).

Nuestro estudio pretende dar luz en este campo desde la perspectiva canónica-histórica. Es necesario buscar las raices hispanas en los temas principales, $y$ hemos podido detectar en estos supuestos autores (Marca, Van Espen, etc.) un neto influjo de nuestros escritores del XVI-XVII.

Respecto a la ortodoxia de los planteamientos borbónicos, mantenemos que no es esta la cuestión esencial ya que los principios y fundamentos de políticos y tratadistas tenían sus raíces en los juristas de que fueron y son considerados ortodoxos. El gran defensor, fuente de los posteriores historiadores de la heterodoxia borbónica extranjerizada, exclama, pues asi cree verlo en las fuentes: “ Oh si hubieran podido levantar la cabeza Ceballos y Salgado!. ¡Cómo se hubieran avergonzado de verse citados por Campomanes y Llorente! $\rightsquigarrow(3)$. Estos autores y los restantes tratadistas del siglo XVIII eran conocedores de los precedentes hispánicos. No hubo ruptura ni cambio de sentido sino evolución y entre las menos heterodoxas del siglo.

\section{SIGLO XVIII Y CAMBIO DE MENTALIDAD}

T. Egido quiere ver en el siglo XVIII dos corrientes claras en el regalismo español. Una más arraigada en el poder del monarca y sus prerrogativas en los asuntos eclesiásticos. Otra en la acentuación del poder episcopal como base de una auténtica reforma de la Iglesia. Mayans aparece incluido en este segundo grupo "episcopalista y reformadorw(4). 
Sin embargo es muy difícil encontrar esta utilísima división tan claramente separada en los autores, aunque los más cercanos a los favores del rey acentuasen la primera opción. No es, por ello, nuestra pretensión adentrarnos en este campo histórico tan bien estudiado por Mestre, Egido y otros ilustres historiadores. Intento, más bien, ver esas corrientes en nuestros estudios canónicos y civilísticos de las épocas anteriores. No es pura expresión personal, sino una constante histórica de nuestros autores, la que Mayans escribe a Burriel lo que investigó es "sólo lo favorable al rey como rey, y no al rey como buen rey, y a los obispos, clero y pueblo de toda la nación; ninguno de nosotros dos (su hermano Juan Antonio y él) seremos traidores al rey, ni a la Iglesia, ni a España»(5).

La afirmación de T. Egido(6) de que hubo un cambio de mentalidad en el siglo XVIII respecto a la regalía de patronato, no puede defenderse (si consideramos algunos autores canonistas españoles del XVI, para no remontarnos más lejos). El planteamiento, como afirma el autor citado, se basa en las conclusiones de A. de la Hera de que la cita de Mons. Molines era un avance cualitativo (no sólo más regalias, sino el contenido de las mismas) a las anteriores centurias. El avance cualitativo consistía en que en XVIII "no tenía el rey de España por indulto o privilegio, sino por verdadero derecho de patronato ex fundatione et donatione, y que, por lo mismo, no podía ser despojado de él,(7). Pero bastará para demostrar que la afirmación es insostenible un texto del XVI:

Reges gothi... construserunt sacra templa et ecclesias: ubi divina officia celebrarentur dotemque eis constituerunt: et ornamenta plurima ministrarunt: Ex que ius patronatus in eisdem ecclesiis presertim cathedralis acquisierunt: et specialiter sibi reservarunt»(8).

Como podemos comprobar no hay diferencia en el planteamiento. Todavia se explicita más la idea, si cabe, en Alvarez Guerrero: «construxerunt... constituerunt... ministrarunt», y por ello "adquirieron el derecho de patronato".

Pienso que Egido, como otros muchos (de la Hera, Domínguez Ortiz, incluso el mismo Menéndez Pelayo), se han dejado llevar más de las consecuencias políticas de la guerra de Sucesión que de la repercusión intelectual de la presencia borbónica, y en cualquier caso, no han puesto en duda lo defendido por los grandes historiadores anteriores. Estos últimos 
no quisieron concluir lo que los mismos hechos y documentos, que conocen, nos demuestran. Egido, aunque critica esa actitud, cae a veces en los mismos planteamientos, que explícitamente dice rechazar. Así escribe:

"No es cuestión de insistir en el anacronismo de visiones arcaicas de una llustración importada(9), y con ribetes de heterodoxia(10) cuando hoy en dia está más que claro que la española hunde sus raíces en tiempos bastante anteriores a la llegada de los Borbones....(11).

Es valiosa su afirmación sobre la diversa metología con la que trata el XVIII y los anteriores siglos: en los Austrias se consideran informes, tratados bien estructurados; y en la Borbones correspondencia, informes confidenciales. $Y$, por otra parte, los historiadores consideran como disputas dogmáticas o cismáticas, lo que está en litigio cuando se trata de "regalías contra reservas", cuestiones disciplinares, o temporales(12), porque no hay un cambio extraño al pensamiento español, las diferencias entre imperio y sacerdocio son antiguas. Ya decia Melchor Cano en su informe:

"La primera razón es, por la fidelidad que los reyes deben a sus reinos, y referencia al nombre de Dios, al cual privaron de amparar y defender las tierras que están de su mando y gobierno, de cualquier persona que pretendiera hacerles fuerza y agravio...".

La segunda razón es... uno de los mayores males... seria que vuestra majestad perdiese el crédito...

La tercera razón... que, con título de reverencia y respeto a la Sede Apostólica y sombra de cisma y religión, dejásemos de resistirles y remediar los males que nos hace, con los mismos temores que nos asombrarán cada y cuando quieran...

La cuarta razón es lo que importa la defensa y remedios de los males a la religión cristiana y es la misma Sede Apostólica...

La postrera razón... los inconvenientes... son inciertos y dudosos, y el mal que se sigue de dejar desierta esta indefensión u remedio es cierto y manifiestor(13). Como se puede comprobar leyendo este informe, del 15 de noviembre de 1555, no hay dificultad en separar las dos esferas, temporal y religiosa, pero, dada la conexión entre ellas, el problema se suscita en cómo se defiende una sin destrozar la otra, (que es lo principal). Se trata de dos mandatos divinos. La superioridad del religioso radica en ser de mayor 
importancia, en su trascendencia, pero ello no impide que sea corregido, ya que el "tutor habría de dejar su oficion y "desamparar a sus pupilos", si no pusiese los remedios necesarios. No podemos concluir que «no nos defendemos de nuestros superiores y padres (el papa), sino que la tal defensa sea más comedida, más acatada y moderada, que con los otros".

No está este pensamiento fuera del contexto ideológico de su tiempo. En 1536 se publica en Valencia un Libro de Alfonso Alvarez Guerrero(14) sobre la necesidad de un concilio y reforma de la Iglesia,

"...y que a vuestra majestad (Carlos $V$ ) toque y convenga instar y procurar el bien universal de la cristiandad por ser cabeza de lo temporal y príncipe de los príncipes... por eso sería necesario que congregándose concilio general, o no congregándose, de parte de vuestra majestad se pidiese al papa que guardase los derechos y estatutos y decretos de la lglesia....(15).

Y que el emperador deba poner remedio, contra los abusos de algunos "clérigos que son semejantes a lobos ambrientos en el avaricia de adquirir beneficios eclesiásticos: a diestro y siniestro". Al tratar del modo como se pueden remediar dichos males añade:

"Mas esto también podría cesar facilísimamente (el recurrir a Roma "con mil injustísimas citaciones") porque estatuyendo vuestra magestad en España una Ley: que [no](16) se pudiese intimar citación de Roma sin que fuese vista en el Consejo de Castilla. Y en Aragón en el Consejo de Aragón; luego no habría más citación por vía de molestar. $Y$ así hay un statuto en el Reyno de Nápoles. De manera que si una citación del papa va en el reino de Nápoles: el que la lleva la presenta en el consejo corateral (sic)(17) de vuestra magestad. Y si al consejo le parece cosa justa: luego manda que se intime a quien va: lo cual es cosa utile.... $x^{(18)}$.

Este tema había sido tratado por Diego de Alava y Esquivel en su tratado De conciliis universalibus, en el cap. 29 , en el que habla de "consuetudo maxime perniciosa» de advocar a la curia Romana «in prima instancia» causas beneficiales y otras, incluso las de poca cuantía. Establece el modo correcto de proceder: primera instancia al Ordinario, apelación al Metropolitano y, una vez usados estos medios, se podria apelar a Roma(19). Hemos señalado este autor como uno de los precursores del sistema de apelaciones tridentino, y será vuelto a citar posteriormente ya que no se 
tendria muy en cuenta este decreto del Concilia20). En carta a Blas Jover decia Mayans:

"Recientemente me ha venido un libro de D. Diego de Alava y Esquivel, Obispo de Avila, De Conciliis universalibus.'Es una mina oculta de la que los franceses han sacado todo el oro que nos venden como propio en sus libros modernos»(21).

El ciclo parece ya cerrado. Autores españoles que defienden la autonomía de lo temporal y la necesidad de reforma.

Extranjeros que beben en nuestras fuentes y que nosotros debemos detectar lo que es suyo y lo que han sacado de nosotros. El testimonio de Mayans es interesantísimo: nos venden lo nuestro como suyo.

Pero ¿podemos afirmar como Unamuno: "lo moderno es aquello tan antiguo que nadie recuerda", o, dicho en otros términos, encontrar una constante de estos temas en los juristas españoles?.

Nuestra respuesta es afirmativa. Sin embargo, antes de pasar a su estudio, queremos señalar otro punto de interés. ¿Cómo tratan nuestros autores la procedencia del poder de la iglesia en lo temporal?. La respuesta puede ser significativa de una época por las dominantes, no por la originalidad.

Dice el Conde de la Cañada(22):

"...Es notorio que todos los bienes temporales de la república estuvieron en su origen bajo de su potestad; y que su distribución y adquisición por los medios de ocupación y de otros que señalaron las leyes, se debió igualmente a las supremas potestades temporales... y así no hay otro título para poseer y gozar los bienes profanos, que el que nace de la potestad pública civil...".

Con esto pretende justificar la intervención de los tribunales civiles en asuntos, en este caso la herencia de clérigos, de la Iglesia. Podria parecernos el planteamiento propio de este siglo. Veamos lo que dice otro civilista, Alfonso de Azevedo (1598), citando a otro más antiguo Pedro Rebuffe (1487-1557).

"Jurisdictio Ecclesiastica mater est temporalis jurisdictionis... La justicia Eclesiastica. Quam matrem jurisdictionis temporalis, et ei obligatam obedire, asserebat Bald. relatus et secutus per Rebuffum in concordata Regni Franciae. I. Parte in proemio, in gloss. filios, pag. 24 in mediocri 
impresione, ubi et ipse Rebuff. inquit hodie filiam velle suffocare matrem, quod quam odibile sit..... Y más adelante afirma:

"Nam sicut luna recipit claritatem a sole, non Sol a Luna, ita Regalis potestas authoritatem a sacerdotali, non e contra recipiat...(23).

Como podemos comprobar el planteamiento del origen, aunque solucionado diversamente, es el mismo y las pretensiones de que uno prevalezca sobre otro no son nuevas en la sistemática de los juristas españoles. El testimonio del autor de Montpelier, que nace seis años después de que pase esta ciudad a Francia, es claro: "hoy la hija quiere sofocar la madre". Quizá se pueda responder que esto era en el XV-XVI entre "algunos" tratadistas, pero no estaba en la práctica de la corona. Aunque la afirmación se tendria que matizar mucho(24), lo que no podemos olvidar es que no fue doctrina extranjera y de "heterodoxia» importada, sino que nace y crece entre los pensadores nacionales.

\section{CONSTANTES EN EL PENSAMIENTO ESPAÑOL.}

Como dice Agustín de Asis(25), la "constante" que aparece en la historia se Ilama "tradición", y añade: La tradición es lo que del pasado de alguna forma actúa o vive en el presente(26). En ese sentido, podemos encontrar constantes que permanecen, con más o menos pujanza en el campo intelectual o político. Dice Francisco Puy Muñoz:

"Un estudio estadístico seriamente hecho de las autoridades que manejan los escritores del XVIII, estamos convencidos que arrojaría, en esta época, por resultado una mayoría aplastante de autoridades de la Escuela Española, una minoria amplísima de autoridades deducidas de la tradición jurídica de la cristiandad, y solo un pequeñísimo tanto por ciento de nombres de la revolución european(27).

Todo el que se acerca y lee esta literatura y la del siglo anterior ve como cierta la anterior afirmación. No resaltemos el conocimiento de la literatura extranjera, ya que otros lo han hecho hasta casi hacernos perder el sentido de nuestra propia cultura(28).

Lo curioso es que, por diversos motivos, se ha querido mantener esta concepción extranjerizante de nuestro pensamiento regalista borbónico. 
A pesar de que los autores que lo defienden, de una forma y otra, han reconocido la constante histórica de este pensamiento. Así dice Menéndez Pelayo:

"Nuestros más famosos regalistas prácticos corresponden al reinado de Felipe IV «(29).

De la misma manera opina I. Martín:

«Durante los reinados de Felipe III y Felipe IV se multiplicaron los recursos de fuerza y a los tiempos de este último monarca corresponde el florecimiento de los más destacados regalistas prácticos y la publicación de los más famosos tratados, como los de Cevallos, González de Salcedo y Salgado de Somoza, que constituyen las fuentes doctrinales y los estimulantes más poderosos de la práctica regalista de su tiempo y de todo el siglo XVIIIs(30).

Otros autores ${ }^{(31)}$ defienden claramente ese sentido constante de nuestra línea regalista. Quizá por eso nos extraña el interés de algunos en mantener la originalidad (por estar desvinculado de nuestra historia) del regalismo borbónico y el escaso reflejo de la doctrina hispánica.

Como hemos dicho, llama poderosamente la atención que, a pesar de la neta explicación de los estudiosos, todavía hoy se habla del "afrancesamiento" que supuso la entrada de los borbones en España.

Como cualquier cambio de dinastía estable, provocó una serie de influencias que anteriormente no estaban marcadas. Sin embargo en el campo intelectual es mucho más difícil precisarlas, ya que sí se conocían esas corrientes de pensamiento (la corriente hispánica) y nunca fue abandonado.

Algunos han querido ver una desconexión, en el XVII, de la cultura europea, pero han olvidado que las posesiones en el centro del continente, el control de media Italia, no podía crear un desconocimiento de lo producido en los centros culturales de la época. Dejemos al margen el aspecto estrictamente científico-experimental. Pero en los demás campos vemos obras de españoles impresas en los centros más influyentes de la época: Venecia, León de Francia, Roma, Nápoles, París, Amberes, Frankfurt, etc. sin mentar los de la peninsula, o, incluso, de América.

También produce sorpresa, la insistencia en el cambio ratificado de heterodoxo sufrido con la entrada borbónica(32), que ha servido de base 
para afirmar la no hispanidad del regalismo que aflora, con matices nuevos, durante el siglo XVIII. Atribuir a de Marca, Fleury, Van Espen, Febronio, etc. el cambio de planteamiento del problema de las relaciones Iglesia-Estado, no coincide con la lectura de los tratadistas españoles del XVI, XVII y XVIII, ya que en estos últimos se ve, por una parte, una preocupación por el problema, y por otra, un conocimiento de las fuentes y tratadistas anteriores.

La formación en "utroque iure" de la gran mayoría de los autores hispanos señala el interés de conocer no sólo lo canónico, para dar una respuesta, en estos casos, de materias mixtas o públicas, sino de tener también en cuenta la legislación "estatal». Y se ha visto la misma como correctora de las arbitrariedades de la «corte Romana", o, "curia papal». Nunca niegan la autoridad del papa, pero es tónica general, en ellos mitigar el absolutismo curial, afirmar que las cuestiones disciplinarias (no olvidemos que habría muchísimas patrimoniales o que podrian afectar al hoy Ilamado "orden público" vg: derecho de asilo-inmunidades etc.). Debian tener como pauta las decisiones conciliares, sin dejar de estudiar los derechos adquiridos, costumbres, privilegios, de los lugares y de la corona. Otro problema que suscita interés entre nuestros autores de los siglos XVI-XVII es la distancia, y lo que lleva parejo consigo: la obrepción y subrepción en la petición de rescriptos. Constante es la preocupación de que las causas sean juzgadas en primera instancia ante el ordinario, y que pasen las menos posibles a Roma. El "derecho comparado" es ya tenido en cuenta para ver el modo de solucionar algunos problemas y, por lo demás, el Derecho de patronato ya se detecta en los Reyes Católicos.

Otro tema que aparece en todos estos siglos (XVI-XVIII) es el nombramiento de Obispo, interés de que sea nacional (por lo peligroso de la no residencia o por razón de premio a servicios prestados, no por su valía, etc.) en apoyo del desarrollo del derecho de presentación por parte del rey.

La retención de bulas será la fórmula de una situación práctica que viene ya de los Reyes Católicos, y que éstos heredaron de los de Aragón. ¿Qué retención más clara que la de negar a un obispado o no aceptar una sanción?. No podemos olvidar las tensiones entre el Imperio de Roma, y después, entre los Reyes de las Españas y el papa, para atender lo que supuso el desarrollo del "placet» o «exequatur». 
Podemos concluir diciendo que, dado el nivel de estudios monográficos, el "regalismo» del XVIII no es consecuencia de la entrada borbónica. En la tradición juridica española están todos los elementos que fueron usados por los defensores de las regalías (regias), que no se puede hablar de ruptura o heterodoxia entre los autores del XVIII. Ciertamente algunos acentuaron algunas propuestas, pero éstas tenían bases en autores españoles anteriores. No debemos confundir la "autonomia de los temporal» del Vaticano II, con una situación histórica en que estaban entremezclados algunos asuntos y no por la sola razón de ser mixtos, sino porque la misma vida del Estado y la Iglesia los habia unido.

\section{IGLESIA ESPIRITUAL}

La necesidad de clarificar el papel que desempeña la Iglesia dentro del nacionalismo, que aparece con el Renacimiento, hace que el deseo de desvinculación de lo terreno sea signo de la reforma necesaria. Tales planteamientos se discutirán en el tiempo de la lucha protestante y se agudizarắn posteriormente.

¿La Iglesia tiene que poseer?. ¿Todo lo terreno pertenece al Estado?. ¿Cuál es el límite de las dos potestades?. Según se dé una respuesta sobre qué es la Iglesia, ¿comunidad visible o comunidad espiritual?, habrá una concepción de la misma vida, en el tiempo, de la comunidad de creyentes(33).

Posteriormente (S. XVII) cuando los reyes católicos colaboran e implantan la reforma (España, Austria, Francia...) la escuela regalista tuvo su lógica. Los que implantan o ayudan a implantarla ¿no tienen derecho a intervenir en la vida de la Iglesia?. ¿No son ellos los que deben ser los portadores de lo eclesiástico en lo temporal?. La intervención regalista (sin llegar a cisma) podría suponer un control de la Iglesia en su desarrollo institucional. Amortización-desamortización; Regalismo-reserva; Fuero competente-control de todos los tribunales; Fin de los bienes- los bienes asunto terreno, etc.; son puntos que los juristas-canonistas tienen que ir clarificando. La lucha de este siglo radica en el intento de clarificar hasta dónde llega cada jurisdicción(34) en los asuntos mixtos. 
En el siglo XVIII se manifiesta de forma más visible el deseo de esa Iglesia espiritual. Se pretende separar de la misma la preocupación terrena. El rey, católico siempre, es el encargado, el responsable de esa dimensión eclesial. Hombres como G. Mayans abogan por ello(35). Con matiz de fino jurista, quiere que la jurisdicción eclesiástica sólo afecte al campo espiritual. Su reforma de la Iglesia va por ese camino. De esa forma se evitaria que las censuras se convirtiesen en armas temporales( ${ }^{(36)}$ y se lograría que la Iglesia volviera a la antigua pureza y libertad(37), que desapareciera la vida religiosa como un medio de subsistencia(38), etc. Sin embargo, otros ven la Iglesia espiritual como el medio de incrementar el poder absoluto del rey, y no paran hasta ver todos los aspectos de la vida ciudadana controlados por el mismo(39). La Iglesia espiritual, será equivalente de la Iglesia relegada al culto, a la predicación con ciertos requisitos. Hasta dónde llegó este extremo lo podemos ver en el emperador José II, el Rey Sacristán, o en la segunda mitad del S. XVIII en nuestra patria(40).

\section{AUTHORITAS SUPREMA}

Ya los juristas medievales estudiaron el doble principio, que enmarcaba la autoridad de los príncipes (secular o religioso), "quod principi placuit legis habet vigorem" y príncipe "legibus solutus est". Según tales afirmaciones, como bien matiza G. Giacchi(41), el principe no está sujeto a la imposibilidad de "mutatio legum", aunque no por ello deja de estar sujeto a las leyes. Hay un paralelismo, dice Duns Escoto(42), entre la ley natural y los actos extraordinarios de la providencia, que actúa según la ley pero tiene poder para actos fuera de ella. Sin embargo este poder absoluto será moderado por otras instancias: costumbres, leyes, privilegios, etc. No se prescinde de la suprema potestad sino que hay otros problemas implícitos: obrepción y subrepción, colaboración en el pecado...

Hay intervención del poder laico (regalismo) y los juristas lo justifican porque hay mentira o ocultación de la verdad en las preces, o porque el papa actúa como mero hombre y no como representante de Dios(43). ¿Se puede defender y propagar la injusticia?. ¿Se debe colaborar con el pecado?. 
Estos temas y otros parecidos se plantearon ya en el canonista medieval, que fue recogida por nuestros tratadistas del XV y XVI. Podemos verlos en Juan López de Palacios Rubios, Martín de Azpilcueta, Alfonso Alvárez Guerrero, Diego de Covarrubias, Domingo Soto, Melchor Cano, Juan Roca de Avila y otros muchos.

Por ello la afirmación de que el «estudio del origen del poder de la lglesia, hasta concluir que tal poder proviene en realidad de los príncipes seculares, o que ha sido extravasado por Roma más allá de los limites que Cristo señalaw(44) no es correcta, y esto atribuirlo al tiempo del absolutismo regio no es exacto. Hay suficiente material entre nuestros autores para ver que este problema es tan antiguo como la formación de las nacionalidades y el derrumbe de la concepción medieval, que, como hemos afirmado, constituirá el fundamento de su desarrollo posterior.

Las polémicas entre el Emperador Carlos $V$ y el papado, por ejemplo, nos muestran el estado de opinión de la época. En carta del 15 de enero de 1548, dice el emperador al papa Paulo III:

"No podemos dejar de maravillarnos muy mucho que su Santidad, se olvide en esto tanto de lo que toca a su oficio y dignidad queriendo mezclar esto con lo de la fe y remedio della.... (45).

La mezcla de intereses espirituales y materiales caracterizará toda la evolución de las relaciones entre las dos potestades en España. Desvincular estos dos puntos sería no tener capacidad para atender el "leiv motiv" de ellas.

Las relaciones entre los Reyes de España y el papado no estarán ensombrecidas por la falta de reconocimiento de suprema autoridad de la Iglesia. Aún en los primeros momentos de plena teología conciliarista provocada por el cisma, no se deja de aceptar al papa como cabeza de la Iglesia, y las críticas a Roma van siempre unidas al reconocimiento de su papel de ser el Factor de "unidad" de la Iglesia y el supremo administrador de ella(46). Constante que llega hasta nuestro siglo XVIII, pasando por los tratadistas (incluso los más regalista) del XVII: Cenedo, Cevallos, Salgado de Somoza(47). No se rechazará la figura del papa como principalisima en la vida eclesial, aunque no será con la precisión que algunos quieran exigir antes del Vaticano I. Sin embargo, tampoco existirá todo el rigor, por parte 
de otros, en lo que después se verá en la Constitución Gaudium et Spes del Vaticano II respecto a la "autonomia de lo temporal".

CURIA ROMANA-PAPA

La distinción entre el Romano Pontífice y la Curia no es jansenista como afirma E. Rota,

"l giansenisti solevano fare una curiosa distinzione fra la sede e il sedente. In virtú di essa, il ribellarsi al sedente diventava lícito purché si conservasse rispetto verso la sede! E' evidente che questa distinzione autorizzava comodamente qualqumque ribellione. Essa valeva per i vescovi contro i pontifici, per i popoli contro i principi!»48).

Aunque es brillante la exposición y sugestiva, no coincide en el tiempo; esta distinción es antigua en el derecho español, como muy bien nos hacen notar nuestros historiadores(49). Podemos afirmar que no es original de los jansenistas esta exposición y que la jurisprudencia española durante muchos siglos la habia empleado para defenderse de las pretensiones del rey de Roma sobre el control de Italia. Y constituirá uno de los puntos de influjo hispánico en el planteamiento de Van Espen sobre la necesaria intervención del papa en los asuntos eclesiásticos.

Las luchas de Carlos $V$ en tierras de Italia están llenas de esta secuela jurídica. La crítica a Roma va más bien dirigida, en el XVI y XVII, contra la organización política o lo que pudiera parecer vinculada a ella.

Todo ello volverá a complicarse con motivo de la guerra de los treinta años (1618-1648). En el XVIII, la guerra civil y, posteriormente, el interés por las posesiones italianas hacen que el problema se reproduzca. Pero debemos separar, de una vez, lo que se ha venido llamando jansenismo, y lo que se puede entender como problemas teológicos, jurídicos, políticos del siglo, e incluso de escuela. De otra parte, querer atribuir a los «jansenistas" todo lo que con visión posterior al Vaticano I se entenderá como herético, o cercano, no tiene fuerza histórica, ni reflejo en el pensamiento de la época.

El mismo Menéndez Pelayo precisa: 
"No se trata alli (crisis entre Felipe II y Paulo IV) de regalias ni de límites de las dos potestades, ni de cosa espiritual o espiritualizada, sino de cuestiones internacionales con el papa considerado como soberano temporal, del cual dijo Domingo de Soto: "Cuando se viste el arnés, parece desnudarse la casulla, y cuando se pone el yelmo encubre la tierra". Y lo mismo los juristas que los teólogos, así Gregorio López como los Maestros Mancio y Córdoba y el mismo Soto cuando declaraban lícita la guerra así defensiva como ofensiva, bien claro dan a entender que no ha de ir encaminada contra el pontífice sino contra el rey de Roman(51).

D. Marcelino, como otros estudiosos, después de afirmar este hecho, lo olvida, creyendo que el pensamiento dominante del XVIII ha sido algo extraño, extranjerizante. Los estudios actuales ya van dando una luz diversa sobre el problema del regalismo histórico en España. Así A. Mestre desarrolla, con gran maestria, la raiz hispana de la llustración(52) y su extensa bibliografía al respecto ha abierto un nuevo modo de leer este siglo.

El campo juridico de la escuela creada por G. Leclerc, en la Universidad Salesiana de Roma, ha ayudado a la comprensión de esa influencia hispánica en la Europa Central(53). Van Espen es estudiado dentro del marco de influencia que ha recibido y desde la presencia en su pensamiento de Nicolás Garcia (XVII), Agustín Barbosa (1589-1649), Luis Gómez (14841553), Diego de Covarrubias (1512-1576) y sobre todo Francisco Salgado de Somoza (1595-1665).

Neta tradición hispana que se puede ver en los siglos XVI y XVII y que después será recogida por los tratadistas del XVIII, tanto hispanos como centro-europeos. Un discípulo de Leclerc, Santiago Alonso, ha estudiado el autor más influyente de las corrientes regalistas posteriores: Francisco de Salgado y Somoza(54). Alonso señala la preferencia de Salgado por citar a autores españoles, aunque no por ello olvida a los extranjeros(55). Francisco Puy, al estudiar nuestro siglo XVIII, ha querido ver, también en el derecho, la neta influencia de sus antecesores(56). Entre los más recientes historiadores podemos ver el citado Teófanes Egido(57) que tan agudamente ha valorado esta época y su vinculación a las raices propias hispanas.

Todos estos autores, y otros muchos citados por los mismos, nos señalan que las virtudes y defectos del XVIII español deben buscarse en la misma escuela hispánica, fundamentalmente. El conocimiento histórico 
de autores extranjeros no hace olvidar, quizá matizar, como todo hecho histórico y de pensamiento, las estructuras fundamentales propias. Incluso, como ya hemos señalado, en los autores que se llaman decisivos por modificar nuestra forma de pensar, vemos la influencia de tratadistas hispanos. Ya hemos destacado su presencia en Van Espen y por él en Febronio(58).

Es evidente, asimismo, la presencia de Covarrubias en el galicano(59) Pedro de Marca. Pero no es Covarrubias el único español conocido y citado por el autor francés, tan significado en la polémica con el papado $y$, sobre todo, en lo referente a las relaciones francesas con Roma.

Además de S. Isidoro, Torquemada, y los Concilios españoles, Marca cita a Vitoria(60), Martín de Azpilcueta (Navarro)(61), Molina(62), Pedro Barbosa(63), Suárez(64), Bovadilla(65), Salgado de Somoza(66) y otros(67).

\section{REGALISMO-CONCILIARISMO}

Cuando en el S. XVIII vemos una reviviscencia del conciliarismo nos hace recordar la vinculación que esta teoria ha tenido con el desarrollo de la intervención del laicado dentro de las estructuras de la Iglesia. No debemos olvidar que el modelo conciliarista no era puramente clerical o episcopalista, el concilio era tenido como la reunión de la Iglesia general (laicosclérigos), para la búsqueda de respuestas generales; era la representación de la lglesia(68). Por eso es lógico que, después de siglos de intervención laical, XVI-XVII español, terminase con una "tendencia conciliarista" expuesta con claridad por Mayans. La evolución de la teoria conciliarista, mitigada si se quiere, conecta con un regalismo (igualmente respetuoso con el derecho del primado) reformador.

La constante crítica de la curia, por su preocupación más política que religiosa, como enemiga de los intereses españoles en la península itálica, hizo que permaneciese viva no sólo en la casa de los Austria sino en los momentos difíciles de la guerra de Sucesión. Las decisiones papales, o de su curia, eran vistas más por el interés terreno que por su neta misión primacial dentro de la Iglesia. 
Sin embargo, no debemos confundir, desde el punto de vista jurídico, y tal vez histórico, entre la preocupación de los juristas españoles por aplicar el concilio de Trento en algunos momentos de discusión con Roma, pero acentuando el intento de la curia, no del papa, para poder ejercer su poder arbitrario(69), y el interés conciliarista. El concilio en la Iglesia siempre es fuente de derecho y es potestad suprema, y cualquier ataque al mismo está dirigido contra la misma Iglesia(70). El concilio, reunión de cabeza y miembros (de otra forma sería, sin cabeza, conciliábulo), es infalible; esto nadie to ha negado. Las dificultades empiezan a surgir cuando se intenta valorar el papel del papa frente a la Iglesia universal o en relación con el concilio. Otro aspecto importante es la responsabilidad de hacer cumplir el concilio, que se ha cargado sobre el rey. El mismo Mayans afirma que es tradición teológica española el reconocimiento de la infalibilidad de la Iglesia católica (después de Dios) que no es católica sin su cabeza el papa(71).

Reconoce Mayans que la autoridad del papa es inferior a la del Concilio, "Sentencia entonces vialida (X.XVI) en España, y aún defendida hoy por el clero de Francia, que nadie se atreverá a decir que es herejem(72).

Si además de todo este problema, discutido entonces, aunque los teólogos españoles del XVIII defendiesen la infalibilidad, añadimos la dificultad regalista e intervencionista del rey, entenderemos cómo el conciliarismo podía ser una forma de soslayar el problema. Decir que el Papa está sujeto al concilio, no es lo mismo que decir que el Concilio está sobre el Papa, aunque muchas veces puede aparecer como sinónimo(73).

La polémica sobre este punto la desarrolla A. Mestre ${ }^{(74)}$ con gran precisión. Es el acercamiento de las dos grandes lineas que se funden en este siglo, el regalismo (el rey garante del Concilio) y el Conciliarismo (más o menos defendido en todas sus consecuencias).

A veces da la impresión de que el ideal medieval, de la cristiandad, a pesar de toda la secularización renacentista, vuelve a aparecer en toda esta polémica.

La "potestas indirecta" de Bellarmino o Suárez podrá llegar a ser una "potestas indirecta" del rey en los asuntos espirituales(75) es decir, el deseo de hacer un reino (no imperio) donde "si las almas son de Dios los cuerpos son del rey ${ }^{(76)}$. El conciliarismo medieval, respuesta a un cisma 
(x. XIV), pasa a deseo de concilio para reforma (s. XV-XVI)(77), de una necesidad de implantar el concilio (s. XVII) y una vuelta al valor del Concilio (doctrina y disciplina) y del poder del rey en defender a sus súbditos de la arbitrariedad de la Curia Romana (x. XVIII).

\section{ORTODOXIA Y REGALISMO}

Los autores que han tratado estos temas, algunos magistralmente, han tenido en cuenta más los aspectos históricos, que, por decirlo de alguna forma, los jurídicos. Ha prevalecido el interés de destacar, como Q. Aldea, el carácter que las relaciones entre el Estado español y la Iglesia católica tienen bajo las Austrias, inspiradas en una ortodoxia católica de los gobernantes, que sirvió de defensa del Estado frente a las teorias heterodoxas del sistema regalista(78).

Sin entrar en la discusión del comienzo del regalismo, en tiempo de Ios Reyes Católicos o anteriormente ${ }^{79}$ ), debemos ir afirmando que la pretensión de que ha habido un cambio de razones para la intervención del rey en asuntos eclesiásticos (o mixtos; según la tendencia del autor) no es exartainol.

Li. canonistica española del XVI y XVII tiene en alguno de sus autores, por lo menos los estudiados, una clara manifestación de que el derecho no viene solamente por concesión papal, sino por la estructura interna del derecho y deber del rey.

No podemos generalizar y debiéramos hacer un estudio detallado de todos aquellos derechos que se han presentado como derechos regalistas. El código de Derecho canónico, canon 3, dice claramente:

"Los cánones del código no revocan en lo más mínimo los pactos celebrados por la Sede Apostólica "con diversas naciones"...".

Que un rey busque la costumbre pactada, o su derecho (en una legislación muy dispersa), no debe extrañarnos, y no puede darse un valor regalista heterodoxo sin más. El mismo canon dice: "por lo tanto, dichos pactos continúan en vigor como hasta el presente, sin que a ello obsten las prescripciones de este código". 
Cuando no es Código sistematizado sino bulas, que van surgiendo como respuestas concretas a situaciones especiales, no resulta extraño que se quiera mantener el derecho adquirido. Pacta sunt reservanda, es un principio que debemos tener en cuenta en la mentalidad de esta época. Si el rey proteje a la Iglesia, tiene el derecho de comprobar que es la Iglesia quien habla. La dificultad de ver esa vinculación a lo eclesiástico, no a la política; la dificultad de las comunicaciones; la falta de un derecho administrativo eclesiástico coherente; el planteamiento de cristiandad (no se va a tribunales paganos sino a tribunales de hombres creyentes: de Iglesia); todo esto empaña una visión clara de la situación de la época. Querer afirmar por ello que era ortodoxa una situación (la austríaca) y no la otra, (la borbónica), no es exacto. La justificación la podemos ver claramente expresada en la evolución historica de los tratadistas estudiados. Las citas de autores anteriores nos hacen ver la continuidad en el pensamiento juridico, pero, antes de estudiar este punto, queremos señalar algo más: el valor de privilegios, derechos y costumbres vigentes.

Estos conceptos, según dice Postius(81), se concentraron en el concepto de "disciplina eclesiástica de España, disciplina vigente en España, y otras análogas, que son el refugio doctrinal del viejo regalismo hasta nuestros dias para sostener sus intromisiones en la jerarquian. Ha habido un interés constante por ver estos puntos como medio para alcanzar fines ajenos a la legislación canónica. Sin embargo, el abuso de los privilegios, derechos o costumbres, no debe verse solamente en la práctica de los mismos (situación que se reitera en la historia) sino en la interpretación, y como consecuencia, en las prácticas abusivas de los mismos. Queremos destacar la importancia de los tratadistas que, con sus teorias, han influido en la marcha de las Cancillerías, tribunales y órganos de gobierno de la nación. Hecho que observamos con frecuencia en los siglos XVI-XVIIXVIII.

Quien, como Alfonso Alvarez Guerrero, pertenece a los organos de gobierno de Nápoles, o Francisco Salgado de Somoza (1595-1665) con cargos importantísimos como presidente del Consejo Real de Castilla, o el mismo Cardenal Luis de Belluga y Moncada que, a caballo de los dos siglos y casa, de Austria y Borbón, fue el defensor de los derechos de la Iglesia en la decisión de sus propios problemas. Todos ellos, y muchísimos más, han 
sido hombres estudiosos, conocedores del problema e influyentes en la marcha de la política, tribunales, etc. del país. Su influencia, en lo que eran posesiones de la casa de Austria, es notoria. Al igual, la comunicación de estudios de una a otra parte del continente es evidente y el conocimiento de autores extranjeros, lo podemos comprobar por los libros que aparecen en las bibliotecas españolas.

No podemos afirmar rotundamente que la extranjerización y la heterodoxia vinieron con la casa de Borbon: el pensamiento juridico español habia desarrollado ampliamente los conceptos de que venimos hablando, con mucha anterioridad. Mi interés, ahora, no es destacar la ortodoxia o no de ciertas propuestas regalistas, sino más bien ver si estas propuestas están o no en nuestros autores, no sólo como hechos, que sí lo están claramente (control estatal de los documentos de la Santa Sede uregium exequatur", patronato Real, lucha contra las reservas pontificias, recursos de fuerza, etc.)(82), sino como base doctrinal, que de la Hera no ve, en tiempo de los Austrias.

O. Giacchi es uno de los autores que, con mayor brillantez, han descubierto la vinculación entre el concepto de imperio medieval y el Estado absoluto(83). La lectura atenta de los distintos autores nos muestra esta afirmación, ya que tiene que pasar por el desarrollo de la independencia de los reyes herederos del "imperium", del poder imperial: la historia, el derecho, incluso la teologia, entraron en juego para demostrar, en un primer tiempo, la no vinculación a la obediencia imperial (pueden verse comentados los hechos, entre Carlos V y Francisco I, en los tratadistas de la época)(84), para después desarrollar los propios derechos: "esclusiva... al menos in teoria, l'unica organizzazione política e comunità civile esistente e possible per quel territorio e per quei subditi»(85).

AUTORES EXTRANJEROS E INFLUENCIA HISPANA

Diego de Covarrubias y Leiva (1512-1577) es uno de los españoles que más han influido en canonistas y civilistas posteriores.

Aunque es considerado ortodoxo, influyó en el desarrollo regalista de Pedro de Marca (1594-1682)(86) y Van Espen(87) entre otros. Siendo tan impor- 
tante en este campo, y en otros aspectos, todavía falta un estudio que señale su presencia en la canonística posterior, tanto española como extranjera.

Covarrubias podemos verlo citado por Marca, ocho veces en su obra(88) alguna de ellas implícitamente, pero su influencia es grande. Reconocido por Marca en su libro sitado:

"Sed summus ille Jurisconsultus nos docet»(89).

"Qua de re graviter scripserunt Covarrubias et Rebuffus noster variis in locis (90). $^{90}$

"Hanc sententian tuentur celeberrimi auctores Covarrubias et $\mathrm{Na}$ varrus»(91). Cuando cita a Covarrubias añade, casi siempre, algún adverbio en el que resalta su importancia "recte observat Covarrubias" «egregie observabit Covarrubias»(92). Todo ello nos indica el alto aprecio que tenia de su doctrina. Hasta qué punto influye en el desarrollo del pensamiento de Marca, excede los límites de nuestro trabajo. Su presencia no es pequeña, aunque nosotros la hemos podido destacar más en muchos apartados que los citados, pero se debiera hacer una justificación que no es del caso.

Marca no sólo conoce a Covarrubias ${ }^{(93)}$, sino a otros, al igual que nuestro derecho e historia ${ }^{\{4\rangle}$. Cita a S. Isidoro, Victoria, Torquemada, Antonio Agustín, Vázquez, Navarro, Barbosa, Suárez, Bovadilla, Salgado y otros. (cf. supra).

Es de destacar su actitud ante los hispanos:

"...qui vicini nobis sunt, et qui, licet a novis plerisque dissentiant, in hoc tamen consentiunt..." No es sólo una aceptación de sus doctrinas, que distan mucho del planteamiento galicano, a ultranza, de Marca, sino un reconocimiento de que los supuestos y las soluciones distan mucho del planteamiento de las suyas. Una cosa es la autonomía, aún con errores, de lo temporal, como diriamos hoy, y otra es su supremacía sin otro límite que la voluntad del príncipe. En Marca el despotismo tiene instrumentos suficientes para dominar la Iglesia a su arbitrio.

La influencia de Diego de Covarrubias en la obra de Van Espen, podemos verla estudiada, en parte de sus obras, por Leclerc(95). Encuentra su presencia en los siguientes tratados De benificiis ocho veces(96). De judiciis, delictis et poenis eclesiasticis cinco veces(97). En sus tres obras polémicas Tractatus de censuris ecclesiasticis, Tractatus de promulgatione 
legum ecclesiasticarum, Tractatus de recursu ad principem, aparece frecuentemente citado Covarrubias y otros autores españoles como Salgado de Somoza y Jerónimo Cevallos.

Como nota Francisco Layrent, este apoyo en la autoridad de doctores que escriben en un país en que está la Inquisición tiene una doble virtualidad: no se le puede atacar de herejía y no puede ser despreciado por la Santa Sede(98). El planteamiento no es ilógico pero inválido, ya que olvida que, aunque no fueron puestos en el Indice por la Inquisición española Salgado de Somoza y Cevallos(99), sí lo fueron por la romana, si bien posteriormente fueron revocadas las condenaciones $\left({ }^{100)}\right.$.

Sin embargo, no solamente debemos valorar estas referencias por su cantidad. Un análisis profundo de las obras citadas demostraria la gran importancia del pensamiento de Covarrubias en el desarrollo del de Van Espen.

Si partiéramos de Diego de Covarrubias y Leyva (1512-1577) no encontrariamos dificultad para hacer el desarrollo de su influencia en los autores posteriores. El estudio merece un tratado especial. No nos seria difícil encontrar su pensamiento en autores españoles y extranjeros, en los que su poderosa inteligencia y aguda sensibilidad jurídica ha dejado huella(101). Sin embargo, queremos ver el conocimiento de otro autor coetáneo, que, siendo netamente ortodoxo y no regalista, ha servido de autoridad para defender posturas que historiadores modernos llaman regalistas. Alfonso Alvarez Guerrero (1502-1576), citado anteriormente, escibió un Tratado sobre el Concilio y Reforma de la Iglesia(102), que tradujo posteriormente al latín(103) (versión que conoció Benedicto XIV)(104), en la que tiene en cuenta la retención de bulas. El pretende que sea el modo no anárquico, que habian practicado los reyes de Aragón y después los Reyes Católicos(105), sino según se realizaba en Nápoles.

«Mas esto (citaciones injustísimas a Roma) podria cesar facilisimamente: porque estatuyendo vuestra majestad en España una ley: que no se pudiese intimar citación de Roma sin que fuese vista en el Consejo de Castilla. Y en Aragón en el Consejo de Aragón: luego no habría más citación por vía de molestar....(106).

Esta obra, junto a dos más del autor(107) le sirvieron de base para un nuevo libro(108). Una y otra obra fueron conocidas por autores posteriores que las citan y tienen en cuenta su doctrina. 
Pedro de Cenedo (s. XVI) conocedor de los juristas y canonistas anteriores de los que hace una "Collectanea". Más que poner su propia opinión expone, como dice el título, un fichero de temas y éstos tratados por autores que él estima como importantes en doctrina. Recoge quinientos catorce autores y obras anónimas. Trabajo ingrato para quien lo hace, pero utilísimo para el interesado en conocer el "status quaestionis" de la época.

Conoce el "Tractado" de Alvarez Guerrero y lo cita asi como su "Thesaurus»(109). Dice:

"Et quidem rei publicae Christiane optium utileque esset quod principes seculares obtinerent privilegium a Sede Apostólica, ut literae citationis et aliae Bullae obtentae a Romano pontifice antequam executioni mandentur in partibus, examinentur in Regiis tribunalibus, eruditissime advertit Doctor Guerrero de Consilio c. 12 ves, mas esto también podría cessar....2110).

Como podemos comprobar, sin profundizar más, el tema es antiguo y solucionado en algún reino de la Corona (Nápoles) con la retención, como nos dice Guerrero en el citado c. 12(111). El camino está abierto; falta que se aplique la defensa natural, el derecho antiguo (también en Aragón y Castilla), o la costumbre inmemorial para que se vaya introduciendo paulatinamente en los canonistas y civilistas hispanos y de ellos en los extranjeros.

Jerónimo Cevallos (1560) también cita el "thesaurus", el mismo capitulo que Cenedo, "cap. 35, n. 14 et 25 et 27 »(112).

Y a su vez Cevallos es fuente de inspiración (copia literalmente muchos pasajes)(113) de Francisco Salgado de Somoza (1595-1665). La importancia de este autor en la canonística extranjera la podemos ver en $G$. Leclerc(114) (Marca, Van Espen), y en su incidencia en la española en Santiago Alonso(115). Estudia la presencia de Salgado de Somoza en : Ios tribunales regios(116) en el Cardenal Belluga(117), Pedro González Salcedo (XVII)(118), Francisco de Torreblanca (1645)(119), Juan Castillo de Sotomayor (XVII)(120), y en el Conde de la Cañada (XVIII).

Alonso también conoce la influencia de este autor en José Covarrubias (s. XVIII)(122), aunque no lo estudia por parecerle que se «limita, a su obra, a una fría yuxtaposición de máximas regalistas con enfoque eminentemente práctico»(123). Quizá sea este el mejor argumento: los "prácticos" 
del siglo XVIII recurrían a los autores del XVII, nada originales por depender de tratadistas anteriores, para poder defender el sistema de comportamiento (regalista) de los tribunales, en los casos en que hubiera retención de bulas o recurso de fuerza.

\section{BALANCE PROVISIONAL}

No podemos afirmar, como hemos ido anotando, que el regalismo borbónico surja de una influencia extranjera y como una novedad que se apoya más en sus derechos mayestáticos que en concesiones (privilegios) pontificios(126).

Al comprobar las fuentes de los tratadistas y los autores consultados por los mismos, descubrimos una constante en todos ellos: Conocimiento de nuestras leyes canónicas conciliares (Toledo especialmente), costumbres inmemoriales (que algunas se confirman en Concilios, sínodos visigodos), derechos adquiridos sea por concesión o por prescripción.

La crisis de las relaciones Iglesia-estado viene por una evolución de la estructura de ambos y por razones históricas muy precisas, aunque complejas en su exposición(127).

Coinciden muchos historiadores del derecho en ver en el siglo XVI, y en especial sus tensiones religiosas, las bases para un resurgir del Estado absoluto(128). El deseo del monopolio de una sola confesión, las dificultades surgidas y las luchas provocadas por ello, ayudan a la secularización de la estructura del Estado; lo que servía para determinar el ámbito de las dos potestades llevaría a una escisión entre ellas. El pensamiento regalista borbónico sólo será una evolución del pensamiento occidental.

Ya hemos señalado que no es exacto afirmar que la distinción entre "sede" y "sedente" era jansenista, pues ya era conocida en la canonística hispana. Incluso el mismo "parecer de la Junta sobre abusos en Roma y Nunciatura, Madrid 20-IX-1632,(124) afirma:

«...en la persona del pontífice concurren dos representaciones: una de Papa, sucesor de San Pedro; otra de príncipe temporal y que la potestad eclesiástica le pertenece al pontífice por ordenación divina y la temporal por derecho humano y donaciones de los Emperadores....(125). 
No sólo es del parecer de Cano, Soto, sino también de una comisión formada en su mayor parte por eclesiásticos, doctos, ortodoxos. No es el "desenfado" de Cano, según parecer de Menéndez Pelayo(126), sino la serenidad de una discusión meditada.

En nuestro estudio, hemos podido comprobar que los canonistas y civilistas de los siglos XVI-XVII y XVIII tienen en cuenta los estudios anteriores, de los que dependen. Si hay una lógica influencia extranjera, no por ello pierde originalidad y olvida sus raices. Hasta qué punto lo extranjero incide en nuestros jurisperitos merece un estudio aparte. Habria que señalar con mayor extensión la influencia previa de los hispanos en ellos, ver su aportación a la canonística, y ponderar hasta qué punto son incorporados al razonamiento jurídico español.

Sin embargo, creemos que hemos destacado la línea continuada de nuestros autores en señalar que los derechos Reales, respecto a la Ílesia, no son puramente algo que viene por concesión de Roma, sino que el mismo derecho de la Iglesia les ha reconocido el papel que desempeñan dentro de ella. Se llamará costumbre inmemorial, privilegio, derechos adquiridos, etc. Todo ello será la justificación de la intervención de nuestros reyes en asuntos eclesiásticos.

Quizá esta frase de José Covarrubias que creemos sincera, no retórica y falsa, resuma la actitud de muchos autores del siglo XVIII:

"Mi objetivo ha sido reducir a máximas, no sólo lo que previenen los Sagrados Cánones y Leyes del Reino sobre los recursos de fuerza y protección, sino también lo que escribieron con tanto acierto los señores Ramos del Manzano, Covarrubias, Salgado, Salcedo y otros Jurisconsultos que forman épocas en la Jurisprudencia nacional»(129). 


\section{NOTAS:}

(1) A. DE LA HERA, Regalismo en «Diccionario de Historia Eclesiástica Española», dirigido por Q. Aldea, T. Martín y J. Vives, Madrid, CSIC, 1975, p. 2067; TEOFANES EGIDO, Regalismo y relaciones Iglesia-Estado en el siglo XVIII: "Historia de la Iglesia en España" dirigida por Ricardo García Villoslada, Madrid, BAC, 1979, tom. IV. p. 138-139 y los autores alli citados.

(2) MENENDEZ PELAYO, Historia de los heterodoxos, Madrid, BAC, 1966, especialmente t. II, p. 471-558.

(3) M. PELAYO, Historia... p. 407.

(4) T. EGIDO, Regalismo (BAC. IV) p. 150.

(5) G. MAYANS Y SISCAR II, Epistolario. Mayans y Burriel, ed. A. Mestre. Valencia, Artes Gráficas Soler, 1972.

(6) HERA, p. 139 nota 42.

(7) id.

(8) ALFONSO ALVAREZ GUERRERO, De bello iusto et iniusto, Napoli, Mansaneda 1543, fol. 48 y $48 \mathrm{v}$;; id. Tractatus de modo... 1545, c. XIV; PALACIOS RUBIO, JUAN, Repetitio in rubricam et capitulum per vestras de donationibus inter virum et uxorem... Valladolid, J. de Homiel, 1503. In introductione, n. 26, Vease Q. ALDEA, Iglesia y Estado en la España de/ siglo XVIII, Comillas, VP., 1961, p. 295.

(9) Cf. ANTONIO MESTRE, Ilustración y reforma de la lglesia, Valencia, Artes Gráficas Soler, 1968.

(10) Cf. M. PELAYO, O. c.

(11) T. EGIDO, o. c. p. 130. Véase también pp. 125, 126, 134, etc.

(12) ib. p. 131.

(13) B.A.E. tom. 61, pp. 198-203.

(14) A.A.G. Tractado de la forma que se ha de tener en la celebración del general Concilio y acerca de la reformación de la Iglesia... Valencia, Fco. Diaz Romano, 1536.

(15) O. c. fol. 48.

(16) Afíadida en la edición de 1537. Errata de la 1536.

(17) "colateral" suprimida en la edición de 1537.

(18) O. c. fol. 47.

(19) DIEGO DE ALAVA Y ESQUIVEL, De conciliis universalibus, ac de his quae ad religionis, et Reipublicae christianae reformationem instituenda videntur... en colofón: GRANATAE, s. e. 1552.

(20) Cf. A. MESTRE, Ilustración y reforma... o. c. p. 271 ss.

(21) G. Mayans a Blas Jover, Oliva 8-I-1746, citado por A. MESTRE, o. c. p. 359.

(22) CONDE DE LA CAÑADA, Observaciones prácticas sobre el recurso de fuerza, tomo II, Madrid, Of. Benito Cano, 1794 (2. ed.).

(23) ALFONSO DE AZEVEDO, Comentariorum juris civilis... Lugduni. Apud. fr. Deville, 1737, Cib. 1. tit. III, in legem quintam, n. 1, 2 y 4.

(24) Cf. TARSICIO DE AZCONA, La elección y reforma del episcopado español en tiempo de los Reyes Católicos, Madrid, CSIC, 1960. 
(25) Prólogo a la obra de FRANCISCO PUY MUÑOZ, Las ideas juridicas en la España del siglo XVIII (1700-1760), Granada, Universidad de Granada, 1962.

(26) O. c. p. III.

(27) O. C. p. 170.

(28) FRANCISCO PUY MUÑOZ, El pensamiento tradicional en la España del siglo XVIII (1700-1760), Madrid, I.E.P., 1966.

(29) MENENDEZ PELAYO, Historia de los Heterodoxos, p. 403.

(30) I. MARTIN, Panorama del regalismo español hasta el Concordato de 1953, en "Revista de la Facultad de Derecho de la Universidad de Madrid» f. I. (1961) 282-283.

(31) Cf. FRANCISCO PUY, en las obras citadas supra.

(32) Cf. A. DE LA HERA, Regalismo, pp. 2066-2068. MENENDEZ PELAYO, Hisforia de los heterodoxos.

(33) Cf. H. JEDIN, Historia del Concilio de Trento, Navarra, EUNSA 1972-81, 4 vol.

(34) Cf. S. ALONSO, El pensamiento regalista de Francisco Salgado de Somoza (15951665), Salamanca, CSIC, 1973; G. LECLERC, Zeger-Bernard Van Espen (1646-1728) et l'autorité ecclésiastique, Zurich Pas Verlag, 1964.

(35) A. MESTRE, llustración... p. 399.

(36) Ib. p. 402.

(37) Ib.

(38) lb. p. 73

(39) O. GIACCHI, Lo stato laico, Milano, vita e pensiero, 1978.

(40) AA.VV. Historia de la Iglesia en España, tom. IV, Madrid, BAC, 1979.

(41) O. GIACCHI, Lo stato..., p. 20.

(42) Citado por O. GIACCHI, o. c. p. 21.

(43) Cf. T. EGIDO, El Regalismo y las relaciones..., p. 127; Q. ALDEA, Iglesia y Estado..., pp. $60-61,160,209-210$.

(44) A. DE LA HERA, Regalismo..., p. 2067.

(45) ARCHIVO HISTORICO ESPAÑOL, Colección de documentos inéditos para la Historia de España y de sus Indias, t. 1: El Concilio de Trento, 1530-1552. Selección y transcripción de Manuel Ferrandis y Miguel Bordonau. Madrid, A. de E.H.S. de Valladolid, 1928, citado por ATILIO GARCIA MELLID, La constitución cristiana de los estados y el Concordato españo/, Madrid, Ed. Nacional, 1955, p. 113.

(46) Cf. P. CENEDO, Collectanea ad lus Canonicum, Caesaragustae, Apud. M. X. Sánchez, 1592, pp. 11-12; DIEGO DE ALAVA Y ESQUIVEL, De Conciliis Universalibus..., Granatae, s. e., 1552, fols. $61 \mathrm{v}-62 \mathrm{v}$.

(47) Cf. S. ALONSO, El pensamiento regalista..., pp. 137-138, 166-174.

(48) ETTORE ROTA, Le origini del Risorgimento (1700-1800), vol. II, Milano, 1948, p. 756; G. LECLERC, o. c. p. 348.

(49) Cf. A. MESTRE, I/ustración... o. c. P. 277; A. DE LA HERA, Regalismo... pp. 2066-68; S. ALONSO, El pensamiento..., pp. 46 y 261; Q. ALDEA, Iglesia y Estado..., p. 189.

(50) C. A. MESTRE, llustración... pp. 383-386. 
(51) M. PELAYO, Historia de los heterodoxos..., p. 399. Sobre el parecer de M. Cano ib. pp. 400-402.

(52) A. MESTRE, Ilustración... o. c.

(53) G. LECLERC, Z. B. Van Espen... o. c.

(54) S. ALONSO, El pensamiento regalista... o. c.

(55) Entre los italianos cita a Menochio, Giurba Surdo, Escacia, Lanceloti, Marta, etc. y entre los franceses los más citados son P. Rebuffe, Carlos Grassis.

(56) Especialmente en: F. PUY, El pensamiento tradicional en la España del XVIII: Madrid, I.E.P., 1966; Las ideas jurídicas en la España del XVIII (1700-1760), Granada, Universidad de Granada, 1962.

(57) Historia de la Iglesia en España, t. IV... o. c.

(58) Cf. S. ALONSO, El pensamiento... o. c. p. 229-232.

(59) Cf. infra.

(60) P. DE MARCA, De Concordia sacerdotii, seu de libertatibus Ecclesiae Galicanae..., Venetiis, Roboreti, 1763, pp. 33, 118, 173 y 176.

(61) o. c. p. 72 y 99.

(62) o. c. p. 68

(63) o. c. p. 98 .

(64) o. c. p. $98,99,115,173$.

(65) o. c. p. 169.

(66) o. c. p. $99,297$.

(67) o. c. "Antonio Agustin" p. 88; "Vasques" p. 115; "Cordubes" p. 118; véase también p. 169. «Simancas» p. 173; “Enrique» p. 297.

(68) T. EGIDO, Regalismo..., o. c. p. 151; A. MESTRE, Ilustración... o. c. p. 266-275; Q. ALDEA, Iglesia y Estado... o. c. p. 189 notas.

(69) Testimonio de este supuesto lo encontramos en el regalista, F. Salgado de Somoza, cuando exige la firma del papa "de su puño y letra" para la validez del rescripto avocatorio, cf. S. ALONSO, El pensamiento regalista de F. Salgado de Somoza, Salamanca, CSIC. 1973, pp. 137$138 ; 261$.

(70) Cf. A. MESTRE, I/ustración... pp. 266-275.

(71) G. Mayans a Agustin Sales. Oliva 23-IX-1764 en A. MESTRE, o. c. p. 269.

(72) G. Mayans a Sales. Oliva 8-III-1763 en A. MESTRE, o. c. p. 269.

(73) Cf. Q. ALDEA, Iglesia y Estado... pp. 192-193 y 399.

(74) A. MESTRE, Ilustración..., pp. 270-273.

(75) Cf. S. ALONSO, El pensamiento..., p. 269.

(76) Conde Duque de Olivares, citado por S. ALONSO, El pensamiento..., p. 258.

(77) Cf. H. JEDIN, Historia del Concilio de Trento... tom. I.

(78) A. DE LA HERA, Regalismo..., o. c. p. 2066.

(79) I. MARTIN, Contribución al estudio del regalismo en España en REDC 3 (1191-1208) (1951).

(80) Cf. Q. ALDEA, Iglesia y Estado..., o. c. p. 190; A. DE LA HERA, o. c. p. 2067. 
(81) J. POSTIUS Y SALA, El Código canónico aplicado a España. Madrid, ed. del Corazón de Maria, 1926 p. 349.

(82) Cf. TARSICIO DE AZCONA, La elección y reforma... 0. c.; A. DE LA HERA, Regalismo... o. c.; S. ALONSO, EI pensamiento regalista... o. c.

(83) Cf. A. AlvaREZ GUERRERO, De bello iusto et iniusto, Neapolis, Mançaneda. 1543. Ultimo capitulo.

(84) O. GIACCHI, Lo stato laico..., p. 16.

(85) O GIACHHI, IC...

(86) Cf. P. DE MARCA, De Concordia sacerdotii et imperii... Venetiis, Apud Ahaedes Balleonois, 1763 , p. 147.

(87) El estudio minucioso de G. LECLERC, Zeger-Bernard Van Espen (1646-1728) et I'autorité ecclésiastique, Zurich, PAS, 1964.

(88) P. MARCA, de Concordia... o. c. pp. 72, 98, 117, 118, 169, 173 y 297.

(89) o. C. p. 147

(90) o. c. p. 118

(91) o. c. p. 72.

(92) o. c. p. 98 . o. c. p. 117.

(93) Cf. o. c. pp. 33, 58, 68, 72, 87, 88, 98, 99, 115, 117, 118, 169, 173, 176 у 297.

(94) Cf. o. c. pp. 62, 151, 153, 157, 169, 352, 441-442, 456, 457.

(95) G. LECLERC, Z. B. Van Espen, especialmente 264-290.

(96) o. c. p. 267.

(97) o. c. p. 269.

(98) FRANCOIS LAURENT, Van Espen, Etude historique sur l'Eglise et l'Etat en Belgique, Paris, 1860 , p. 77 ; cf. O. c. p. 276.

(99) Cf. L. VON PASTOR, Historia de los Papas, t. 29, Barcelona 1910-61, pp. 24-25.

(100) Cf. Z. B. VAN ESPEN, Opera Omnia, tom. VIII, Venise 1769, Consulte du Conseil Souverain de Brabant, dirigido a SAS Maria Isabel de Austria, Gobernante de los Países Bajos, el 12 Febrero 1736. Véase S. ALONSO, o. c. pp. 33-39.

(101) Cf. G. LECLERC, Zeger-Bernard Van Espen. S. ALONSO, El pensamiento regalista de Francisco Salgado de Somoza (1595-1665), Salamanca, CSIC 1973. Ambos estudios llevan bibliografia abundante e interesante.

(102) ALFONSO ALVAREZ GUERRERO, Tractado de modo y forma que se ha de tener en la celebración del general Concilio, $y$ acerca de la reforma de la Iglesia, Valencia, Fco. Díaz Romano, 1536; id. Genova, Bellono, 1537.

(103) H.A.G., Tractatus de modo et ordine generalis concilii celebrandi et de reformatione Ecclesiae Dei, Neapoli, Apud A. de Mançaneda, 1545.

(104) BENEDICTO XIV, De Sinodo diocesana. Roma, Exc. J. G. Salomoni, 1753.

(105) T. DE AZCONA, La elección de reforma del episcopado español en tiempos de los Reyes Católicos, Madrid CSIC, 1960.

(106) A.A.G., Liber aureus... de administratione justiciae, Valentie, Franciscus Romanus, 1536, ID. De bello iusto et iniusto... Neapoli, Ambrosius de Mançaneda, 1543. 
(107) ID., Thesaurus... et speculum sacrorum summorum romanorum pontificum, imperatorum ac regum, Venetiis, 1559 . Se hicieron siete ediciones más: 1563, 1570, 1581, 1586, 1607 , 1608.

(108) PEDRO CENEDO, Collectanea ad lus Canonicum..., Caesaraugustae, Apud M. Ximenum Sánchez, 1592, 1 pars "ad Decretum» pp. 1-96, Secunda pars ad decretales pp. 97-190; Tertia pars ad sextum decretalium, clementenas et extravagante pp. 191-445.

(109) o. c. pp. $7,20,65,99,118$, etc.

(110) o. c. pp. 7.

(111) Cf. D. COVARRUBIAS, Practicarum quaestionum... Valentiae Edetanorum, In officina J. Estevan et Cervera, 1775, c. 33. n. 4 y 6.

(112) J. CEVALLOS, Speculi aurei opinionum comunium contra comunes, Antuerpie, Apud J. Keerbergium, 1623, Y TOM. 4 p. 83 (questio 899).

(113) Cf. S. ALONSO, El pensamiento regalista..., o. c. pp. 160-186.

(114) Cf. supra.

(115) S. ALONSO, o. c. pp. 187-232. donde estudia también su influencia en los autores extranjeros: Van Espen (o. c. 224-229) y Febronio (o. c. pp. 229-232).

(116) o. c. pp. 189-197; BERNARDO QUIROS, Nuevo promotor del real protección..., Salamanca, 1738 pp. 5, 6, 47, 133-134.

(117) o. c. pp. 197-200. Cf. I MARTIN, Figura y pensamiento del Cardenal Belluga, Murcia, 1960.

(118) o. c. pp. 210-214; P. GONZALEZ SALCEDO (Salcedo González), De lege politica eiusque naturali executione tan inter laicos quam ecclesiasticos ratione boni communis, Madrid, 1678.

(119) o. c. pp. 214-216; F. TORREBLANCA, Epitome delictorum in quibus aperta vel oculta invocatio daemonis intervenit, Granatae, 1618.

(120) o. c. pp. 216-221; J. CASTILLO DE SOTOMAYOR, De tertiis debitis catholicis et invictissimis Regibus Hispaniae ex fructione et rebus omnibus quae decimantur, Matriti, 1632.

(121) o. c. pp. 221-223; CONDE DE LA CAÑADA, Instituciones prácticas de los juicios civiles... I Tomo; Observaciones prácticas sobre recursos de fuerza... tomo segundo... Madrid, Benito Cano 1794 .

(122) o. c. p. 208: J. COVARRUBIAS, Máximas sobre recursos de fuerza y protección, Madrid, viuda de Ibarra, hijos y compañia, 1788.

(123) ib. Personalmente creemos que es más que una yuxtaposición.

(124) Editado y comentado en profundidad por Q. ALDEA, Iglesia y Estado, pp. 241-399.

(125) o. c. p. 249.

(126) M. PELAYO, Historia de los heterodoxos, t. Il, p. 402. Cf. H. DE LA HERA, Regalismo... o. c. p. 2067.

(127) Cf. DOMENICO BARILLARO, Societá civile e societá religiosa, dalla Riforma alla Restaurazione, Milán, Giuffré, 1978.

(128) D. BARILLARO, ...o. c. p. 31; O. GIACCHI, Lo stato laico, o. c. p. 13 ss., quiere verlo en la concepción imperial del Medioevo.

(129) J. COVARRUBIAS, Máximas... o. c. p. IV. 